\title{
"NEURODERECHOS", PRUEBA NEUROCIENTÍFICA Y GARANTÍA DE INDEPENDENCIA JUDICIAL
}

\section{"Neuro-rights", neuroscientific evidence and guarantee of judicial independence}

Roberto González Álvarez*

Universidad Andina del Cusco

Doctor en Derecho por la Pontificia Universidad Católica del Perú, docente investigador de la Universidad Andina del Cusco, investigador Concytec (grupo CM, nivel III), miembro titular del Instituto Iberoamericano de Derecho Procesal. ORCID iD: 0000-0001-9782-6228. Contacto: rgonzalez@uandina.edu.pe 


\section{Resumen:}

Las neurotecnologías permiten la conexión directa del cerebro humano con un ordenador gracias a una interfaz, por ejemplo, de inteligencia artificial. Uno de los resultados de esta realidad y futuro tecnológico es la mejora cognitiva que crea superhumanos con cerebros y mentes muy superiores a los de las personas normales. El compromiso ético que se pone en juego hizo que la BRAIN iniciative promueva el reconocimiento de "nuevos" derechos humanos Ilamados "neuroderechos". Un superhumano-juez traslada esos problemas éticos al ámbito probatorio.

En este trabajo se establece que solucionar esos futuros problemas no es un asunto de nuevos (neuro)derechos, sino de (neuro)garantías procesales de viejos derechos (acción y contradicción). Un claro ejemplo de esto es la limpieza, naturalidad, normalidad e intangibilidad cerebral y mental del juez para la actividad probatoria como contenido de la "vieja" garantía fundamental de independencia interna del juez.

\section{Abstract:}

Neurotechnologies allow the direct connection of the human brain with a computer thanks to an interface, for example, of artificial intelligence. One of the results of this reality and technological future is the cognitive enhancement that creates superhumans with brains and minds far superior to those of normal people. The ethical commitment at stake led the BRAIN initiative to promote the recognition of "new" human rights called "neuro-rights". A superhuman-judge transfers these ethical problems to the evidentiary realm.

In this paper, it is established that solving these future problems is not a matter of new (neuro)rights, but of procedural (neuro)guarantees of old rights (action and contradiction). A clear example of this is the cleanliness, naturalness, normality and cerebral and mental intangibility of the judge for the evidential activity as the content of the "old" fundamental guarantee of the judge's internal independence.

\section{Palabras clave:}

Neuroderechos - Neurotecnologías - Libertad-Prueba - Independencia judicial

\section{Keywords:}

Neuro-rights - Neuro-technologies - Freedom - Evidence - Judicial independence 


\section{Sumario:}

1. Premisa - 2. Neurotecnologías - 3. Inteligencia artificial y neurotecnologías - 4. Neurociencia y neuroderecho - 5. Los "neuroderechos": ¿un resultado de la amenaza neurotecnológica? - 6. ¿lnventando "nuevos" derechos humanos?, ¿lagunas axiológicas y normativas? o un falso "neuroproblema" jurídico-normativo que inquieta a neurocientíficos -7 . Prueba neurocientífica, neurotecnologías y "neuroderechos procesales" -8 . Lista de referencias

\section{PREMISA}

Son diversos los ámbitos de pensamiento, aproximados a la idea de singularidad tecnológica (Kurzwell, 2012), desde los cuales las nuevas circunstancias de vida y conocimiento humanos justifican exigir el reconocimiento de derechos humanos; por ejemplo, el animalismo, los derechos de los animales (Waal, 2007, pp. 105 y ss.), el humanismo, el transhumanismo, el posthumanismo. En estos espacios culturales, sociales, jurídicos, políticos, científicos, tecnológicos, etc., no se duda en calificar sus exigencias ético-normativas como nuevas y, por tanto, en identificar a esos derechos humanos como "nuevos".

El "animalismo" parte por la defensa de los intereses de los animales a partir de un compromiso de pensar y actuar en favor de los animales dentro de los que el ser humano se identifica como uno más y con un singular proceso de evolución biológica. En esta línea, se diferencia la regulación legislada que protege a los animales delimitando un escenario ético desenvuelto normativamente (derecho animal) de la doctrina filosófica, cultural, política y jurídica para proteger los intereses de los animales; reconociendo en ellos seres libres con dignidad que los hace portadores de derechos sin importar su especie (derechos de los animales).

El "humanismo" se sostiene en la interacción de valores universales del ser humano, es básicamente antropocéntrico, es decir, pensado en oposición y superación de la justificación teológica de las cosas, de modo que no es Dios el centro de importancia, sino el ser humano. Su principal sustento es el conocimiento que empodera al ser humano y le asigna una vida libre y feliz; tan así es que no es raro que en sus líneas de desarrollo se encuentren el pensamiento crítico, el existencialismo o los desarrollos de las ciencias con un gran espacio asignado a las humanidades. Si bien las líneas de la vasta historia del humanismo, las humanidades y la modernidad están conectadas, aquí impor- 
ta el humanismo que diferencia al ser humano de los animales, por lo que el derecho es antropocéntrico sin más, y afronta en la actualidad la condición del superhumano como la del humano mejorada por la ciencia y las tecnologías.

El "transhumanismo" (Widow y Jensen, 2016) se autodefine como un movimiento, iniciativa o proyecto de índole intelectual, cultural y, en el mejor de los casos, científico-filosófico que promueve la apetencia, investigación y posibilidad de usar tecnologías avanzadas (por ejemplo, robótica, nanotecnología, biogenética, neurotecnología, inteligencia artificial, etc.) para el incremento de las capacidades físicas, cognitivas, sensoriales, morales y emocionales de los seres humanos; es decir, para evolucionar del homo sapiens al homo exelsior o, mejor, al homo deus a su vez amanzado por la (r)evolución de una religión digital (Harari, 2016, p. 339), por manipulación genética y mejoramiento tecnológico, es la evolución o supervivencia por "selección tecnológica", para alcanzar un orden de felicidad, óptimas capacidades psicológicas y físicas, longevidad y suprema inteligencia que en el humanismo no se puede tener.

El biohacking es una corriente que confluye en los movimientos del transhumanismo y cíborg. Se trata de impulsar, por un lado, el uso de tecnologías para maximizar las capacidades físicas, cerebrales, cognitivas, mentales y sensoriales del ser humano como su autodeterminación de mejora morfológica y/o biogenética a través de tecnologías médicas, alimentarias o digitales (transhumanismo); y, por otro, los procesos de cambios en los organismos vivos por incorporación de dispositivos tecnológicos (cíborgs u organismos humanos o no humanos cibernéticos).

El "posthumanismo" prescinde de la tecnología y diferencia al sujeto posthumano por su capacidad que supera, excede o rebasa de manera extraordinaria una o más capacidades de cualquier humano; por ejemplo, salud física y metal sostenida o ausencia de patologías, cociente intelectual por encima del nivel más alto del promedio normal y emocionalidad valorativa de la vida y las personas.

Si bien el transhumanismo no ha alcanzado tutela jurídica específica y diferenciada, el panorama regulatorio que se está formando es muy llamativo; así, entre diversos documentos favorables al transhumanismo, cuentan las recomendaciones del Parlamento Europeo (2017) a la Comisión sobre normas de Derecho civil sobre robótica, y los dos informes de 2016 emitidos por la Unión Europea: el primero, Informe final sobre futuros digitales: un viaje a las visiones y desafíos políticos de 2050, refiere el surgimiento de transhumanos en 2050 como consecuencia de los desarrollos tecnológicos de mejoramiento intelectual, físico y psicológico de los humanos; y, el segundo, Señales de cam- 
bios de valor en Europa, impulsores e impacto en las políticas de investigación e innovación de la UE Informe final, refiere la mejora de la condición humana por superación de sus capacidades intelectuales y mentales como el esfuerzo del transhumanismo.

El sentido antropocéntrico del derecho comienza por la idea de que el ordenamiento jurídico, hecho por el legislador humano, regula el comportamiento de los seres humanos naturalmente entendidos (por ejemplo, persona natural, nasciturus, concepturus) o a través de artificios que no dejan de mostrar su conformación por seres humanos (por ejemplo, persona jurídica, patrimonio autónomo, asociaciones no inscritas). Este sentido del derecho, que gira en torno al ser humano, descansa en la mayor expresión del humanismo en el derecho: los derechos humanos.

Hasta aquí se advierte que diversos condicionamientos de la postmodernidad se han ido acumulando de manera clara frente a la comprensión humanista del derecho, en muchos casos como exigencias de superar o ir más allá de la persona humana en la regulación del orden social, vinculando a la naturaleza o lugares u objetos geográficos la noción de sujeto de derecho, condición que se expone también para ídolos, mitos, animales y artefactos con funciones inteligentes; así, un chimpancé en Brasil (Fraundorfer, 2018, pp. 17-25), la naturaleza en Ecuador (artículo 10 de su Constitución) o un sistema digital inteligente (Solaiman, 2017, pp. 155-179) en Arabia Saudí tienen reconocimiento como sujetos de derecho. Es decir, se intenta construir un futuro en el que la condición de transhumano y de posthumano sea un paradigma sobrepuesto a la condición de humano. El ser humano pierde centralidad regulatoria y se mira a otras categorías de interacción jurídica a tutelar como los animales, la naturaleza, la inteligencia artificial (IA), los organismos vivos robotizados, los cíborgs, etc. Ya no es suficiente el establecimiento y creciente reconocimiento de derechos humanos porque los derechos serán animales, transhumanos o posthumanos.

La iniciativa de los "neuroderechos" está enmarcada en la idea de reconocer nuevos derechos humanos (por ejemplo, los derechos a la libertad cognitiva, la privacidad mental, la integridad mental, la continuidad psicológica, la igualdad de acceso a la mejora mental, la protección contra el sesgo algorítmico, etc.) como respuesta a la amenaza del desarrollo de las neurotecnologías. Es decir, en cierto modo, se enmarca en la continuidad del humanismo, pues - como propuesta de reconocimiento normativo a nivel internacional, constitucional y legislativo- no desborda el encuadre de los derechos humanos, sino descansa en intentar alcanzar nuevos derechos humanos. 
Siendo así, los problemas que plantea en el plano procesal y, específicamente, en el derecho probatorio se asumen en el escenario de las pruebas neurotecnológicas (por ejemplo, la declaración testimonial de un superhumano y la valoración probatoria por un juez mejorado cerebral y mentalmente por interfaz a un dispositivo de IA), poniendo a prueba el sistema de fuentes del derecho procesal frente a cambios de la realidad inminentes.

\section{NEUROTECNOLOGÍAS}

Las neurotecnologías son el conjunto de teorías, técnicas, métodos e instrumentos para el aprovechamiento práctico del conocimiento neuricientífico, pero, con una particularidad, siempre que comprendan la conexión directa de cerebros humanos a ordenadores.

Las neurotecnologías son las que permiten la conectividad digital del cerebro gracias a una interfaz cerebro-computadora (Brain-Computer Inerface - $B C l)$, que es un dispositivo definido como:

[U]n sistema que mide la actividad del sistema nervioso central (SNC) y la convierte en una salida (respuesta) artificial que reemplaza, restaura, complementa o mejora la salida (respuesta) del SNC natural y, por tanto, modifica las interacciones en curso entre el SNC y su entorno externo o interno. (Wolpaw et al. citado en Roberts, 2019, p. 3).

Una $\mathrm{BCl}$ es el punto de conexión común entre dos aparatos o sistemas (uno biológico y otro artificial) independientes, su estructura implica i) sensores, que pueden ser invasivos porque comprenden una intervención quirúrgica para la conexión directa de (nano)electrodos en el cerebro (por ejemplo, implantes cocleares, estimuladores cerebrales profundos, el chip implantable inalámbrico de Neuralink) o no invasivos particularmente empleados para decodificar pensamientos, generar imágenes de la actividad cerebral, imágenes mentales o predecir conductas, movimientos o el habla (por ejemplo, electroencefalógrafo, escáneres de resonancia magnética funcional - $\mathrm{fMRI}$ - cascos como el Kernel Flow, gafas, pulseras, diademas); ii) y sistemas de procesamiento (por ejemplo, inteligencia artificial). En la actualidad, los sensores pueden conectar a uno o más sistemas de procesamiento dos o más cerebros, no será raro en el futuro la comunicación y el control remoto de aparatos en forma telepática.

La neurotecnología es necesariamente el resultado de esfuerzos interdisciplinarios en los que conjugan espacios la IA, la nanotecnología, la bioinformática y nuevas áreas (Amoedo-Souto, 2018, p. 93) de investigación 
para i) la generación y manejo de bases de datos cerebrales (neuroinformática); ii) la construcción digital de arquitecturas cerebrales capaces de replicar la funcionalidad neuronal (simulación cerebral); iii) el diseño de computadoras siguiendo los patrones estructurales y funcionales del cerebro humano (informática neuromórfica); y, iv) el uso de robots para simulaciones de funciones cerebrales (neurorobótica).

Este escenario científico y tecnológico de alto desarrollo hace posible esclarecer el poder de la neurotecnología para asumir una lectura de la actividad neuronal que permita decodificar el pensamiento, conectar el cerebro a las redes digitales, hipermedios, en fin, a internet. Esto tiene que ver con el incremento o mejora cognitiva con la orientación de "hacer" superhumanos, sin duda se trata de una redefinición de lo que es un ser humano, dada su conexión cerebral con un dispositivo informático que permita la lectura de sus ondas cerebrales para contactar (aprender, adaptar y gestionar) en tiempo real una base de hipermedios, realidad aumentada, IA, etc.

Pero estos desarrollos neurotecnológicos no afrontan únicamente el reto de lograr superhumanos, también están las industrias de los videojuegos, simuladores, realidad aumentada, militar (por ejemplo, soldados no solo con ausencia mental de miedo al campo de guerra, sino con conectividad cerebral digital para manejar drones, intercomunicarse y ver imágenes satelitales en tiempo real que ayuden a cumplir su misión, etc.,) y, con más importancia, el desarrollo neurotecnológico asistencial, es decir, el desarrollo de órtesis y prótesis para el tratamiento de discapacidades (por ejemplo, sordera, ceguera, mudez, etc.) y patologías (por ejemplo, mal de Parkinson, Alzheimer, adicciones, lesiones cerebrales, parálisis, neurosis, psicosis, epilepsia, esquizofrenia, etc.) en base a la comunicación entre el cerebro y dispositivos electrónicos; por ejemplo, implantes cocleares para eliminar la sordera, extremidades robotizadas, estimuladores de médula espinal que contrarrestan los efectos del Parkinson, etc.

\section{INTELIGENCIA ARTIFICIAL Y NEUROTECNOLOGÍAS}

La forma de enfocar la IA es confusa por los términos empleados en su denominación. Se sabe que los conceptos son las ideas que forman el entendimiento o juicio sobre algo y que como representación mental vincula un significado lingüístico. En el caso de la "inteligencia" aplicada a lo "artificial" se altera el concepto inteligencia, transgrediendo su significado o sentido de capacidad humana (sustancia puramente espiritual) de entender, pensar, conocer, comprender o saber algo. 
En consecuencia, si algo tiene inteligencia, o es inteligente, es debido a que "es humano" o debe hacer las cosas "como si fuera humano" sin dejar de ser biológico (por ejemplo, la inteligencia de un perro), no se puede calificar como inteligente una secuencia de algoritmos condicionales ejecutados por una máquina solamente por referencia a esa función artificial. Es decir, la referencia a esa artificialidad mecánica o, propiamente, esa artificialidad mecánica no tiene o no cumple un rol regulador o normador porque ese trabajo lo hacen nuestros conceptos y sus significados. Tampoco puede promover una ( $r$ ) evolución conceptual o un cambio de significado porque, simplemente, decir "IA" es un oxímoron donde la retórica sobra.

La inteligencia, como el conocimiento o el aprendizaje, es una capacidad cerebral y, por tanto, biológica y no una situación del cerebro que se puede emular. De manera que, por ejemplo, el aprendizaje autónomo de la IA, o aprendizaje profundo (deep learning) no deja de ser una técnica por la que los algoritmos de un sistema en un ordenador replican las interconexiones del cerebro humano como si fuesen conexiones automáticas que permitan identificar patrones y asumir decisiones cada vez con mayor volumen de datos (big data) y mayor velocidad. Esto afianza mayores desarrollos en diversos usos de la IA como la planificación probabilística, aprendizaje automático por árboles de decisión o redes neuronales, reconocimiento de patrones, visión artificial para reconocimiento biométrico, procesamiento del lenguaje para reconocer contextos de un discurso o realizar resúmenes, traducciones, etc.

Al parecer el entrenamiento del sistema sin ser programado explícitamente (machine learning) para acrecentar masivas bases de datos (big data) y el procesamiento ultraveloz de gran cantidad de información que resuelve problemas por cálculos matemáticos complejos se muestra como inteligencia, cuando no deja de ser procesamiento de información por ordenador que, si bien algún día pueda pasar un test verbal, como el test de Turing, o llegar a articular o sumar diversos aprendizajes (superando su "olvido catastrófico" o dificultad del sistema para aprender una nueva habilidad sin perder otra anterior), no significa que sea una inteligencia, esta siempre es viva y, en grado mayor, comprensiva y consciente, algo que le es ajeno al procesamiento artificial de datos que no es ente o ser.

Lo afirmado exige también reconocer que la denominación de la IA como tal ha asumido un rol protagónico en identificar una disciplina científica y una tecnología que, por su equivocado nombre, despierta emociones y expectativas sobredimensionadas que, en todo caso, no dejan de darle entidad a la IA cuando no la puede tener; entonces, un futuro de ciencia ficción en el que el 
descontrol de las máquinas o robots hace que estos dominen o exterminen al animal humano es nada probable.

¿Cuándo se hace una verdadera amenaza la IA? Cuando une su desarrollo y aplicación a las neurotecnologías. El futuro de las neurotecnologías se orienta a la decodificación o lectura de ondas cerebrales para manipular los procesos mentales involucrados en la comunicación, emoción, intención, decisión, aprehensión, memoria, etc., con una clara orientación a mejorarlos radicalmente, esto será posible cuando la $\mathrm{BCl}$ tenga de un lado el cerebro a mejorar y de otro una forma de IA.

La interacción entre neurociencia, neurotecnología e IA ofrece mayores expectativas que cada área por separado porque se abren diversas posibilidades; por ejemplo: i) leer la actividad cerebral humana y escribir información neuronal en el cerebro, ii) la estimulación selectiva de neuronas; iii) la construcción de redes neuronales artificiales de reconocimiento pleno de habla conversacional en contexto, y la decodificación de actividad cerebral para el control sensitivomotor de robots vía $B C l$.

La interacción de la IA con la neurotecnología, si bien no redefine la primera ni hará realidad la singularidad tecnológica, o el momento en que la inteligencia de las máquinas supere a la inteligencia de los humanos, sí pone en juego la inteligencia biológica mejorada cognitivamente y expande, de manera determinante, el contenido, utilidad y problemática de la IA.

La IA como disciplina científica comprende, a su vez, otras disciplinas referidas a i) la programación, planificación, razonamiento de conocimientos, búsqueda y optimización (razonamiento automático); ii) el deep learning o aprendizaje profundo (aprendizaje automático); iii) los sistemas ciberfísicos, de control, percepción, sensores y accionadores (robótica); y, iv) los sistemas de medición de actividad cerebral para conexión real e inmediata con software de IA (neurotecnología).

La IA como tecnología es un sistema de software para la obtención, acopio o recopilación de datos, por actividad digital o perceptiva del entorno, que procesa para lograr información que le permita asumir decisiones óptimas por sí o ayudar a asumir decisiones a agentes biológicos externos o vinculados por conexión directa y real.

Los problemas, riegos o peligros de un futuro distópico a cargo de robots o, mejor, de sistemas informáticos que reemplazan a jueces y abogados humanos (por ejemplo, los robojueces de Estonia), en la misma medida en que se cree que es posible reemplazar o subsumir la compleja arquitectura jurídica (normativa) 
a deshumanizados modelos computables, es decir, los pseudoproblemas de la IA pasan a ser los problemas de un futuro inminente en el que las diferencias entre superhumanos o humanos mejorados cerebralmente con IA a través de una $\mathrm{BCl}$ ponen en juego no solo la libertad y la dignidad de la mente de los sujetos procesales, sino la igualdad de las personas frente a algunos jueces y abogados mejorados.

Las preocupaciones por los desarrollos de la IA que afecten contenidos fundamentales han traído como consecuencia reacciones de gobiernos, compañías tecnológicas e instituciones para asegurar un marco ético de la investigación, comercialización y aplicación de los múltiples beneficios de la IA.

Esto significa que se cuentan desde códigos éticos de corporaciones tecnológicas como Google y Facebook, hasta Directrices éticas para la IA confiable de la Unión Europea que promueven una IA lícita, ética y robusta que, si quiere ser confiable, debe cumplir con ciertos requisitos: i) autonomía humana y supervisión; ii) robustez técnica y seguridad; iii) privacidad y gobernanza de los datos; iv) transparencia o información clara de la naturaleza, resultados, capacidades y limitaciones de la IA; v) diversidad, no discriminación y equidad; vi) bienestar social y medioambiental; $y$, vii) rendición de cuentas o auditabilidad.

Un marco ético amplio al que se han sujetado las divisiones de IA de grandes corporaciones es la declaración de principios cautelares de inteligencia artificial de Asilomar (2017), conformada por los siguientes principios: creación de IA beneficiosa como meta de la investigación; financiación para asegurar que el uso de la IA sea beneficioso; enlace entre investigadores de IA y legisladores; cultura de cooperación, confianza y transparencia en la investigación de IA; evitar errores en los estándares de seguridad; seguridad de los sistemas de IA; transparencia en los fallos, si se causa daño debe poder determinarse la causa; transparencia judicial o explicación satisfactoria y auditable, por una autoridad humana competente, de toda intervención de IA en una decisión; responsabilidad del (mal) uso de la IA; alineación a valores humanos, la IA debe ser compatible con la libertad y dignidad humanas; privacidad personal; libertad y privacidad; beneficio y prosperidad compartidos del mayor número de personas con el uso de la IA; control humano; sin subversión, la IA solo debe respetar y mejorar los procesos sociales no subvertirlos; evitar cualquier carrera armamentística; capacidad de precaución; planificación y gestión de la IA con el cuidado que exige su importancia y la mayor mitigación de riesgos posible; automejora recursiva; bien común.

Un marco específico de la IA en la eficacia de la justicia en la Unión Europea, propiamente para el control y medición de la calidad de los sistemas 
judiciales de los países miembros, es la Carta ética europea sobre el uso de la IA en los sistemas judiciales y ámbitos afines (2018). En esta carta se consagran principios fundamentales para la investigación, elaboración y aplicación de herramientas de IA destinadas al tratamiento de decisiones y datos del Judicial y del Legislativo.

\section{NEUROCIENCIA Y NEURODERECHO}

Tomar decisiones desencadena a nivel cerebral una serie de conexiones neuronales obedientes a ciertos patrones de percepciones que se producen relativamente de manera automática y condicionante de lo que entendemos funciona como libre voluntad, autonomía de voluntad o simplemente libertad (Gava, 2010, pp. 117 y ss.) de decisión.

Hemos pasado de la rígida mirada del psicoanálisis del siglo pasado para atender el subconsciente a contemplar objetiva o empíricamente los resultados de la observación del funcionamiento neurobiológico del cerebro gracias a escáneres que permiten visualizar el funcionamiento cerebral y elaborar mapas de procesos cerebrales tan sofisticados como el conectoma que proporciona análisis tipológicos, de conectividad de núcleos de redes neuronales que integran diversos sistemas sensoriales, es decir, permite la visualización de conexiones individualizadas entre cada neurona y sinapsis, entre los axones y actividad neuronal por regiones cerebrales que facilita, inclusive, la determinación del grado de influencia genética en las conexiones y funcione cerebrales.

El estudio del conectoma ha descrito la ley de eficiencia funcional del cerebro, pues las neuronas y sus componentes ajustan su morfología a lograr el mayor beneficio con el menor tiempo, espacio y recursos o gasto metabólico, el cerebro es un milagro de eficiencia, es decir, de mayores rendimientos en el menor tiempo, esfuerzo y recursos.

En la actualidad se cuenta con un acceso directo a la monitorización y manipulación de la función o actividad cerebral no solo para observarla en la arquitectura biológica, química y eléctrica, sino para manejarla a través de diversos métodos que van desde los estímulos de recompensa hasta la administración de psicofármacos.

Si la neurociencia estudia los procesos cerebrales y condicionamientos mentales que son determinantes en la gestación, desarrollo y exteriorización del comportamiento humano y la neurotecnología permite el uso de los conocimientos neurocientíficos en la conexión del cerebro con un dispositivo que lo 
mejore y, a la vez, mejore su toma de decisiones y el comportamiento humano a que da lugar, el derecho se ocupa de la regulación de ese comportamiento humano y de sus efectos en el grupo social. El neuroderecho (neurolaw) (Picozza et. al, 2014 p. 7; Amoedo-Souto, 2018, pp. 95 y ss) es el punto de contacto entre neurociencia, neurotecnología y derecho, es decir, es el espacio de estudio del comportamiento humano y de sus efectos jurídicos bajo los condicionamientos cerebrales (neuroquímicos, eléctricos, morfológicos) y mentales naturales o inducidos por interfaz con un dispositivo.

\section{LOS “NEURODERECHOS”: ¿UN RESULTADO DE LA AMENAZA NEUROTEC- NOLÓGICA?}

Si bien las neurotecnologías han iniciado su marcha investigativa y comercial principalmente en el ámbito de la asistencia en casos de discapacidad o de tratamientos de algunas patologías, por ello mismo han marcado sus pasos en sujeción a regulaciones (supra)estatales de bioética. De manera que la experimentación neurocientífica y la aplicación de sus resultados obedecen a factores legales médicos que rigen desde declaraciones supraestatales hasta reglamentos muy específicos, por ejemplo, los principios éticos para la investigación médica en seres humanos contenidos en la "Declaración de HeIsinki" (1964); la declaración elaborada por la Comisión Nacional de Estados Unidos para la Protección de Sujetos Humanos de Investigación Biomédica y del Comportamiento conocida como el "Informe Belmont" (1979); las "Pautas éticas internacionales para la investigación biomédica en seres humanos" preparadas por el Consejo de Organizaciones Internacionales de las Ciencias Médicas (CIOMS) en colaboración con la OMS (Ginebra, 2002); la "Declaración Internacional sobre los Datos Genéticos Humanos" de la UNESCO; y en la legislación peruana, la Ley General de Salud N²6842, la Ley de Investigación Biomédica N¹724/2012-CR y el Reglamento de Ensayos Clínicos aprobado por Decreto Supremo N 021-2017-SA. Asimismo, está pendiente de aprobación el Proyecto de Ley N 1724/2012-CR, que propone la Ley que regula la Investigación Biomédica

Conjurar la amenaza del desborde de la investigación, experimentación, comercialización y aplicación de las neurotecnologías, principalmente frente a las libertades individuales en el plano (médico) asistencial, es una labor asegurada desde la protección a nivel legislativo de salud y bioética que existe actualmente. Pero, no sucede lo mismo cuando se trata de los planos de mejoramiento y manipulación del cerebro y de la mente para fines comerciales, educativos, militares, policiales, etc. 
El manejo de la "neuroinformación" o "neurodatos" no solo atañe al cerebro, sino, sobre todo, a la (actividad de la) mente de aquella persona en la que funciona una interfaz entre su cerebro y un dispositivo informático que permita la lectura de sus ondas cerebrales, o decodificación de su actividad cerebral y mental, para conectarse en tiempo real, por ejemplo, a un dispositivo de IA para aprender, adaptar, modificar, gestionar o asumir neuroinformación. Es decir, se trata de una persona humana que está sometida a un sistema de medición de actividad de su sistema nervioso central que se traduce en neuroinformación artificial capaz de ser reemplazada, restaurada, complementada o mejorada para su reinserción en su sistema nervioso central en el que esa neuroinformación procesada (re)asume "naturalidad", lo que en todo caso comprende una modificación de la funcionalidad cerebral y mental en las interacciones internas (a nivel de su propio cerebro, sus propios recuerdos, emociones, paradigmas, etc.) y externas de esa persona (a nivel de interacción social, laboral, etc.).

No solo las personas superinteligentes, o "desproporcionadamente más inteligentes que el promedio", gracias a un chip implantado en sus cerebros, serían una amenaza para la igualdad tanto de inteligencia como de sus consecuentes expresiones en lo económico, laboral, social, etc.; sino también las personas con pensamientos (recuerdos, emociones, paradigmas) implantados 0 sembrados indiferenciables de sus pensamientos naturales, pero, en todo caso, abiertamente manipulados. Entonces, no solo la dignidad del cerebro (igualdad neuronal) y la mente, sino también la libertad de la mente está puesta en juego.

Es una preocupación abiertamente declarada por los líderes de las principales divisiones de neurotecnología de las compañías más grandes del planeta, por ejemplo, Microsoft o Google, el temor por la "desigualdad neuronal", sin duda una preocupación que no es básicamente por los aspectos comerciales, empresariales, científicos o neurotecnológicos, sino legales y éticos. La interferencia (en la semántica más amplia del término "interferencia") de la actividad cerebral y mental de las personas, eliminando y/o implantando pensamientos (recuerdos, significados, ideas, creencias, paradigmas, etc.) es lo que realmente preocupa.

Aun cuando la neurotecnología de asistencia se apoya en una ética de solvente regulación y la IA cuenta con un marco ético bajo el que se viene desarrollando desde hace varias décadas, todo esto resulta insuficiente para las proyecciones evolutivas de la neurotecnología sobre todo cuando se vincula a la IA. Se hace imprescindible una ética de la neurotecnología para evitar i) la manipulación o explotación de las mentes en ámbitos laborales, políticos, comerciales, etc., que alteraría la privacidad mental, la autonomía individual, en 
fin, la libertad de la mente; $y$, ii) la manipulación cerebral para el mejoramiento mental (memoria, recuerdos, big data, soporte decisional de IA, etc.) que rompería el equilibrio de acceso igualitario a oportunidades de diversa índole social, cultural, laboral, económica, política, etc., atentando directamente el contenido de dignidad de las personas.

Conforme el progreso investigativo en neurotecnología siga marchando con el interés empresarial y/o gubernamental, apostando mucho dinero en quien logra las primeras patentes de los grandes cambios que ventilan, se agudizarán los problemas éticos y legales que reflejen la investigación, comercialización y aplicación de estas nuevas tecnologías inexploradas en sus reales consecuencias tanto beneficiosas como violatorias de los derechos fundamentales; pero, en todo caso, previsibles en los contenidos fundamentales que pueden afectar. Por eso, es conveniente anticipar un escenario normativo complementario de los derechos humanos, de los derechos fundamentales y de la legislación especial para conjurar actos lesivos de la libertad y dignidad de la mente.

Según quienes ven la necesidad de nuevos derechos humanos los compromisos éticos de la neurotecnología de mejoramiento cerebral son nuevos, nunca antes imaginados y no comparten solución con la ética de la IA o de la neurotecnología asistencial, y si no se atienden ponen en riesgo el futuro (ético) de sus desarrollos investigativos, comerciales y de aplicación.

Se están alcanzando grandes desarrollos, en el mapeo cerebral y el estudio del comportamiento, con el trabajo de los laboratorios vinculados a la iniciativa de "Investigación del Cerebro a través del Avance de Neurotecnologías Innovadoras" (Brain Research through Advancing Innovative neurotechnologies, abreviadamente conocida como iniciativa BRAIN), que es un proyecto de investigación iniciado en los Estados Unidos de Norteamérica en 2013 para conocer la interacción de las células cerebrales. Para ello, se emplea (el desarrollo de) métodos y herramientas ópticos y eléctricos de mapeo cerebral para conocer ampliamente (y manipular específicamente) las neuronas del cerebro y, principalmente, comprender los pensamientos, los sentimientos, los movimientos, la memoria y algunas principales patologías cerebrales y mentales. En la línea de trabajo de la iniciativa BRAIN, también son muy importantes los desarrollos, en Europa, del Proyecto Cerebro Humano de la Comisión Europea, en China, del Instituto Chino de Investigación del Cerebro (Beijing) y, en Japón, del “Proyecto para dilucidar la imagen completa de la red de funciones cerebrales mediante tecnología innovadora".

Es evidente que, si estos desarrollos traen grandes progresos para aproximarnos, de alguna manera, a los misterios del cerebro, también portan peligros 
tan grandes para la persona humana y la colectividad como solo el poder de acceder, recopilar, compartir, grabar, introducir (escribir o generar), en suma, manipular las emociones, la memoria y, en general, toda información que el funcionamiento del cerebro y la mente podría suponer.

En este escenario se destacan cuatro áreas de preocupación (Yuste y Goering, 2017, pp. 159-163): i) privacidad y consentimiento, para evitar el jaqueo o tráfico de información cerebral y mental; ii) autonomía e identidad, para evitar la manipulación de la voluntad y de las capacidades cerebrales y mentales de modo que se altere la identidad (personalidad o el sentido de sí) de la persona; iii) equidad en el acceso a las neurotecnologías; $y$, iv) igualdad de oportunidades frente a las mejoras cerebrales y mentales para evitar sesgos y prejuicios en investigaciones y aplicaciones de neurotecnologías.

Esta preocupación hizo que en el marco de la BRAIN iniciative se programe otra iniciativa (Yuste et al., 2021), una destinada a la protección de la mente, conducta y recuerdos de la persona: NeuroRights Initiative. Esta iniciativa proyecta tres áreas de trabajo: i) cuatro prioridades éticas para las neurotecnologías y la IA (privacidad, identidad, autonomía e igualdad de las personas); ii) hacia nuevos derechos humanos en la era de la neurociencia y la neurotecnología (el actual escenario de los derechos humanos es insuficiente para las nuevas realidades neurocientíficas y neurotecnológicas, deben añadirse cuatro derechos "neuroespecíficos": a la libertad cognitiva, a la privacidad mental, a la integridad mental y a la continuidad psicológica): y, iii) es hora de los neuroderechos (derechos a la identidad personal, al libre albedrío, a la privacidad mental, a la igualdad de acceso a la mejora mental y a la protección contra el sesgo algorítmico).

Desde la NeuroRights Initiative se auspicia el reconocimiento normativo internacional, constitucional y legislado de cinco "neuroderechos" identificados como "nuevos" derechos humanos: i) el derecho a la identidad cerebral y mental, para prohibir que la neurotecnología transforme la identidad mental; ii) el derecho al libre albedrío, para que las personas no sufran la manipulación neurotecnológica; iii) el derecho a la privacidad mental, porque los neurodatos deben ser siempre privados; iv) el derecho al acceso equitativo a potenciadores mentales; $y, v$ ) el derecho a la protección contra sesgos algorítmicos, debe obligarse al empleo de contramedidas que conjuren sesgos algorítmicos cuando se manejen o desarrollen algoritmos de aprendizaje automático.

La propuesta normativa de esta iniciativa, que es de un grupo de neurocientíficos encabezado por el profesor Rafael Yuste, hizo eco en Chile con la aprobación, por la Comisión de Desafíos del Futuro, Ciencia, Tecnología e 
Innovación del Senado, del proyecto de ley que establece la neuroprotección. Este proyecto comprende reglas mínimas para las investigaciones en neurotecnología, respetando la dignidad humana y exigiendo que el Estado fomente las investigaciones neurotecnológicas y garantice el acceso igualitario a ellas y a la aplicación o uso de sus resultados.

La primera disposición de este proyecto de ley establece como sus objetivos: i) la protección de la integridad física y psíquica de las personas, el derecho a la autonomía o libertad de decisión individual, el derecho de acceso sin discriminaciones arbitrarias a aquellas neurotecnologías de mejora de capacidades psíquicas; ii) el fomento de la investigación neurotecnológica y médico-clínica sujeto a principios éticos de investigación científica y médica para beneficio común; y, iii) el aseguramiento de la información a los usuarios de los efecto negativos y secundarios del uso de neurotecnologías, así como el derecho al control voluntario sobre el funcionamiento de cualquier dispositivo conectado a su cerebro.

\section{6. ¿INVENTANDO “NUEVOS” DERECHOS HUMANOS?, ¿LAGUNAS AXIOLÓGI- CAS Y NORMATIVAS? O UN FALSO “NEUROPROBLEMA” JURÍDICO-NOR- MATIVO QUE INQUIETA A NEUROCIENTÍFICOS}

Quienes promueven la iniciativa de los neuroderechos, más allá de exponer los desarrollos neurocientíficos y neurotecnológicos y sus asombrosas potencialidades, identifican la necesidad de reconocimiento normativo (supra) estatal de nuevos derechos humanos por tres razones: i) la protección normativa existente de la libertad, igualdad y dignidad de la persona, aun cuando comprenda su cerebro y su mente, no lo hace expresamente contra los abusos de la neurociencia y la neurotecnología; ii) existen lagunas axiológicas y normativas sobre los propuestos nuevos derechos humanos llamados neuroderechos; y, iii) si existe una iniciativa bioética que alcanzó, a nivel internacional, el reconocimiento de los derechos biogenéticos se debe conseguir lo mismo con relación a los neuroderechos.

i. El marco normativo no menciona ni es una respuesta a las amenazas de las neurociencias y neurotecnologías. Se propone la regulación de los neuroderechos básicamente por lo siguiente: el uso o abuso de las neurotecnologías de mejoramiento cerebral generan nuevos compromisos de la libertad y dignidad cerebral y mental porque ponen en juego la autonomía individual y la libertad y privacidad mental; y, el marco normativo (supra) estatal no cubre, no menciona, el uso seguro, transparente, beneficioso y 
eficaz de los medios neurocientíficos ni neurotecnológicos. Así, por ejemplo, sí está consagrado a nivel normativo (supra)estatal el derecho a la libertad de pensamiento; sin embargo, esta consagración no comprende las amenazas a la libertad de pensamiento por la neurotecnología o resulta parcial e impreciso porque no menciona que esa protección es frente a las neurotecnologías. Se identifica, entonces, la necesidad de que la libertad de pensamiento se proteja expresamente frente a los medios neurotecnológicos vinculándolos a un marco ético que permita su investigación, comercialización y aplicación bajo la observancia de nuevos derechos humanos, nuevos contenidos constitucionales y nuevos desarrollos legislativos expresamente identificados a través de nuevos derechos: los neuroderechos.

ii. ¿Lagunas normativas? Se trata, sin duda, de una dilucidación de lagunas normativas en el ordenamiento (supra)estatal formulada por bioeticistas y neurocientíficos. De modo que ellos mismos proponen un nuevo marco normativo de derecho internacional, de derecho constitucional y de derecho legislado en los que se protegen y desarrollan los, también por ellos denominados, neuroderechos que no son sino nuevos derechos humanos para proteger el cerebro y la mente.

iii. Se debe emular la iniciativa biogenética para alcanzar sus logros normativos. Los principios contenidos en la Declaración Universal sobre el Genoma Humano y los Derechos Humanos (1997) fueron recogidos en la Declaración Internacional sobre Datos Genéticos Humanos (2003). Es más, los derechos humanos de las ciencias de la vida se consagraron también en la Declaración Universal sobre Bioética y Derechos Humanos (2005), abarcando la protección de un amplio panorama biomédico y científico de la salud y la vida con gran impacto en ordenamientos internos. Esta trayectoria normativa de la iniciativa genética es un ejemplo a seguir por la iniciativa de los neuroderechos, porque estos son la respuesta a nuevos desafíos planteados por la neurociencia y la neurotecnología.

Sobre estos aspectos conviene puntualizar lo siguiente:

i. Los neuroderechos no son nuevos derechos. Los derechos humanos no son ni viejos ni nuevos, en la medida en que la persona humana, para efectos normativos, no es nueva o vieja ni se sujeta a oleadas, cambios o generaciones. Los derechos humanos se reconocen o no se reconocen.

La neurociencia y neurotecnología, como desarrollos del conocimiento científico, presentan nuevos escenarios de realización de los derechos 
humanos de la libertad, igualdad o dignidad. Bien visto, no es un asunto de nuevos derechos, sino de nuevas circunstancias a las que se exponen los derechos humanos de libertad, igualdad o dignidad. No se puede admitir la idea de que la tutela de la libertad del ser humano en el ordenamiento internacional, constitucional y legislado no comprenda esos contenidos frente a nuevos específicos desarrollos tecnológicos.

Si las formas de abuso o uso indebido de esas tecnologías y sus investigaciones son un problema por la novedad tecnológica comprometida puede llegarse: en el plano internacional, a recomendaciones, informes o documentos similares que sirvan a las corporaciones o investigadores en general como pautas de prevención de vulneraciones de derechos humanos; en el plano constitucional democrático de derecho, la consagración de la defensa (entiéndase: protección de la libertad) de la persona humana y el respeto de su dignidad, los derechos fundamentales a la vida, la identidad, la integridad (moral, psíquica y física), el libre desarrollo y bienestar, la igualdad ante la ley, la libertad de conciencia, la libertad de expresión y opinión, la libertad de pensamiento, etc., hacen innecesaria una mención específica a los neuroderechos, máxime que el órgano que hace de supremo intérprete del orden jurídico tiene en su función desenvolver el sentido y espíritu de la Constitución para cubrir cualquier contingencia circunstancial obediente a los cambios de la vida actual por efectos de las ciencias y tecnologías en su más amplio sentido; en el plano legislativo, puede asumirse el caso chileno para establecer las consideraciones de la (in)conveniencia de legislar los neuroderechos, al parecer el mayor éxito del proyecto chileno de ley "sobre protección de los neuroderechos y la integridad mental, y el desarrollo de la investigación y las neurotecnologías" es de mercadotecnia al conseguir posicionarse como el primer país en el mundo en tener esa legislación tan especializada que, evaluada serenamente, es un elenco de disposiciones mayormente prohibitivas de acciones propias a la investigación y aplicación de neurotecnologías con un propósito de utilidad real que seguramente la jurisprudencia y no propiamente a razón de esa ley se ocupará de satisfacer por la alta complejidad de un escenario futuro que, comprometiendo contenidos éticos de siempre, se abre para una tecnología en constante cambio. No debe olvidarse que los altos niveles de abstracción normativa permiten una mayor aplicabilidad a casos individuales, es decir, la alta densidad axiológica de las disposiciones que reconocen contenidos fundamentales permite solucionar casos más específicos que las leyes no pueden detallar. 
ii. Pensar en nuevos derechos humanos conlleva una acusación de laguna normativa, situación que en tiempos de constitucionalismo de principios carece de sentido porque la filosofía del derecho establece la remisión o ruta a los principios como la erradicación de lagunas del Derecho y de la legislación, en tanto la Constitución dogmática asuma su función integradora. A esto se debe sumar que una ley que regule prohibiciones en la investigación y aplicación de neurociencias y neurotecnologías, por muy buena que sea la intención del legislador, puede generar lagunas axiológicas. Es decir, esas lagunas ideológicas en las que existe una norma que no debería existir; en otras palabras, que lo que está ausente no es la norma, sino que su regulación sea satisfactoria, completa y, por tanto, justa.

iii. Emular los reconocimientos normativos sobre bioética o el genoma humano como una ruta preestablecida para iniciativas o proyectos científicos y desarrollos tecnológicos preocupa por la sobreabundancia de propuestas de nuevos derechos humanos que podría significar. Más aún si se considera el exponencial desarrollo científico y tecnológico en las distintas áreas del conocimiento de la vida.

\section{PRUEBA NEUROCIENTÍFICA, NEUROTECNOLOGÍAS Y “NEURODERECHOS PROCESALES"}

Las neurotecnologías (lenca y Andorno, 2017) vistas en el derecho procesal gravitan en la esfera de la libertad y dignidad del justiciable contenidas en el derecho de acción y en sus garantías correlativas como el proceso justo y la tutela jurisdiccional respectivamente. Esto hace que prácticamente no haya espacio procesal que se vea aislado (in)directamente del influjo neurotecnológico, de manera que va desde la libertad de demandar, pasando por la imparcialidad del juez, el contradictorio, el derecho probatorio, la decisión judicial, la impugnación hasta la ejecución procesal. En suma, las neurotecnologías propician nuevas circunstancias condicionantes de la proyección del ejercicio de derechos fundamentales procesales.

En el plano del derecho probatorio las neurotecnologías se presentan en la esfera de la prueba pericial (Nieva, 2013, pp. 176 y ss.) no solo sobre los hechos controvertidos, sino sobre otros medios de prueba, por ejemplo, neurotecnología aplicada a un declarante como parte o testigo para determinar si dice o no la verdad, se trata de una metaprueba que, por ello mismo, tiene muy discutida utilidad.

Tal vez la conexión teórica - y a veces práctica- del proceso con las neurociencias y neurotecnologías se visibilizan con relación a la imparcialidad, la 
verdad en las declaraciones, la valoración probatoria, la toma de decisiones procesales, etc. En todo caso, las explicaciones de la función cerebral más conocidas son las que permiten detectores de mentiras, decodificadores mentales, impresoras cerebrales y escáneres cerebrales.

Los detectores de mentiras son dispositivos de registro y medición de respuestas cerebrales en la función de recuperación de recuerdos de manera que permite establecer indicadores de verdad en los recuerdos recuperados. Estos dispositivos se diferencian por sus modelos tradicionales y de generaciones recientes. Los primeros, como el polígrafo, trabajan por la medición de funciones biológicas como la presión arterial, ritmo cardiaco o impulsos musculares, de ahí que su eficiencia es dudosa. Los últimos, trabajan por imágenes de resonancia magnética funcional ( $\mathrm{fMRI}$ ) o electroencefalograma ( $E E G$ ), proporcionando un alto porcentaje de eficiencia en comparación al polígrafo, pero aún insuficiente para establecer la verdad de los hechos en un caso concreto. Debido a que la medición de indicadores biológicos por un recuerdo o exposición a un sonido, imagen, objeto, etc., no necesariamente es la medición del recuerdo del hecho que está en debate procesal.

Los decodificadores mentales son dispositivos de medición de ondas cerebrales, permiten monitorear y decodificar estados mentales (por ejemplo, concentración, inseguridad, irritabilidad, etc.) para traducirse en imágenes, texto o señales a través de las que se pueden reconstruir las funciones medidas.

Las impresoras cerebrales reconocen la reacción singular cerebral a diferentes estímulos de manera que se permite el reconocimiento de un sujeto por su reacción o función cerebral, asegurando una mayor eficiencia de autenticación.

Los escáneres cerebrales permiten determinar diversos biomarcadores neurocognitivos, por ejemplo, el biomarcador neurocognitivo potencial para el comportamiento antisocial persistente, sugerido a partir de un estudio que concluye en que los prisioneros que, al momento de su liberación, fueron sometidos a tareas informáticas para toma de decisiones prácticas e inhibición de reacciones impulsivas, muestran menor actividad en la región cerebral asociada a la toma de decisiones y la acción (corteza cingulada anterior ACC) y tienen mayores posibilidades de reincidencia dentro de los cuatro años siguientes.

En cualquiera de estos casos se observa que estos métodos, artefactos o dispositivos son no invasivos y su empleo es para decodificación de pensamientos, generar imágenes de la actividad cerebral, imágenes mentales o predecir conductas, movimientos o el habla (por ejemplo, escáneres de resonancia magnética funcional - fMRI- cascos como el Kernel Flow, gafas, pulseras, 
diademas), por lo que los problemas que presentan en el proceso judicial obedecen a las consecuencia de la lectura del cerebro y, en esta medida, los cuestionamientos de su utilidad resultan consistentes, sobre todo, porque el desarrollo que en la actualidad muestran es muy precario para evidenciar "la verdad" de los hechos en el caso concreto.

No obstante, es un asunto completamente distinto cuando se trata de enfocar los riesgos avizorados del empleo de las neurotecnologías que permiten la conectividad digital del cerebro gracias a una interfaz cerebro-computadora que reemplaza, restaura, complementa o mejora las interacciones de un sistema nervioso central; imaginemos de un superhombre juez, testigo, parte, abogado o perito.

Un aspecto importante que plantea este futuro no es el de la IA como ente o amenaza frente al juez, sino es el del juez que, teniendo una interfaz cerebral con un dispositivo de IA, ejercita su función jurisdiccional asumiendo aprehensiones, razonamientos y decisiones de los que no se logra diferenciar lo que propiamente aporta la IA de lo que resulta ser el funcionamiento natural de su cerebro. Se pasa de la solución de identificar siempre "al hombre-juez detrás de los algoritmos" al problema de no dilucidar que "detrás del hombre-juez están los algoritmos".

Se perderá la posibilidad de diferenciar si el razonamiento, discurso y decisión que realiza el hombre-juez es de su natural producción o función cerebral o de la neuroinformación artificial gestionada por la IA con la que su naturalidad mental no se logra diferenciar. La cara visible en la actividad procesal será la del juez, su voz expresará lo que su cerebro ordene funcionalmente, pero esa función cerebral no solo preocupa por lo influida que esté por la IA -al punto que sea esta la que prevalezca en las decisiones y la exigencia de humanidad sea maquillada-, sino porque la neuroinformación puede ser decodificada, leída o escrita, (des)estimulada selectivamente, en fin, manipulada para bien o mal. Es decir, se trata de un hombre-juez que está sometido a un sistema de medición y control de la actividad de su sistema nervioso central con la particularidad de que esta pasa a un formato (de neuroinformación) artificial y, por tanto, con la posibilidad de ser reemplazada, restaurada, complementada o mejorada para su reinserción en su sistema nervioso central de modo que (re)asume naturalidad.

Haciendo a un lado los problemas éticos y legales del superhumano que es juez, importa aquí revisar los problemas del juez que es superhumano, de su funcionalidad evidentemente diferenciada por su condición de mejora cerebral y mental. 
Un juez con una desproporcionada superioridad de inteligencia frente al promedio de jueces no dejaría de ser una amenaza para:

i. La igualdad de los justiciables de acceder a un juez mejorado cerebral y mentalmente (por ejemplo, memoria, recuerdos y análisis de datos con funciones de big data, soporte decisional de IA, etc.) sea por no poder acceder a ese juez o también, precisamente, por lo contrario, por estar en un proceso con un juez superhumano. Se pone a luz el problema de la (des)igualdad neuronal de los jueces.

ii. La independencia interna y externa del juez, porque la $B C l$ permite la manipulación o interferencia de la mente del juez eliminando y/o implantando pensamientos (recuerdos, emociones, significados, ideas, creencias, paradigmas, etc.) indiferenciables de sus pensamientos naturales. Evidentemente esto pone en juego no solo la libertad y dignidad del cerebro y la mente del juez, sino también la libertad y la dignidad de los justiciables por la interferencia de la independencia cerebral y mental del juzgador.

Es conveniente ampliar los efectos de la mejora cerebral del juzgador a otros sujetos que participan en la actividad procesal como los abogados, las partes, los testigos, los peritos, etc., los problemas éticos y legales sobre la igualdad y la dignidad; guardando las diferencias, serían básicamente los mismos que se presentan cuando se trata del juez superhumano.

¿Sería una necesidad anticipar un orden regulatorio procesal para afrontar estos problemas en el derecho nacional? ¿Conviene empezar a tratar la importancia de los "neuroderechos procesales"? Una respuesta a interrogantes similares fuera del ámbito procesal es la que ofrece la iniciativa BRAIN, que se tangibiliza en el desarrollo teórico y, seguramente, más adelante práctico, de los neuroderechos.

Asimismo, es conveniente observar que los neuroderechos comprometen interacciones de vida o circunstancias fácticas que se conectan a contenidos materiales como la privacidad y consentimiento, la autonomía e identidad, la equidad para acceder a las neurotecnologías, y la igualdad de oportunidades frente a las mejoras cerebrales y mentales. Estos aspectos claramente asistirán al escenario procesal configurando el mérito del proceso o esa estructura interna del conflicto que se traslada a la ruta del proceso para la derivación silogística de la norma general y abstracta (que no actuó de manera espontánea) en norma individual (particular y específica) para que actúe en forma forzosa. De manera que, serán materia de conocimiento jurisdiccional en pretensiones de vigor constitucional donde se esclarezcan hechos y derechos y garantías 
fundamentales para la protección no del individuo sino de la Constitución o, mejor, de la persona humana entendida como libertad y dignidad en la letra constitucional.

Pero el mérito procesal sobre neuroderechos no es la única ruta por la que estos derechos se ponen de manifiesto, también están para hacerse notar en el escenario del proceso jurisdiccional en tanto el justiciable es portador de libertad y dignidad que vinculan en sentido positivo (garantías procesales del Estado social) o negativo (garantías procesales del Estado liberal) al Estado en la personificación del hombre juez.

Siendo así, importa sobremanera entender que, en el plano del proceso jurisdiccional, la idea de los neuroderechos se canaliza a la identidad, libertad y privacidad cerebral y mental del juzgador exigida para conjurar su transformación o alteración por neurotecnologías particularmente de IA. Contenidos materiales fundamentales que no se advierten propiamente de novedosos neuroderechos, sino de los derechos fundamentales procesales de acción y contradicción porque las garantías que los hacen efectivos en sus contenidos de libertad y dignidad son expresiones deónticas de obrar negativo, en el sentido de que el juez no puede alterar su independencia cerebral ni mental por injerencia de algún dispositivo de IA; y de obrar positivo, en el sentido de que el Estado asegure una tutela jurisdiccional con jueces igualmente inteligentes en tanto ninguno tiene un tratamiento neurotecnológico para mejorar su inteligencia y sobreponerse a los demás con su superinteligencia.

Exigir derechos neuroespecíficos a la libertad cognitiva, a la privacidad mental, a la integridad mental y a la continuidad psicológica del juez no es en verdad algo nuevo. Con la exigencia de independencia interna del juez se aseguró de que su cerebro no tenga taras mentales como indicadores de racismo, homofobia, misoginia, etc. En esa misma medida que puede entenderse por debajo de una línea sana o normal cerebral y mental, tampoco se puede permitir que el juez tenga una condición cerebral y mental muy superior a la normal, un respaldo de superinteligencia que no es de su naturaleza humana, sino de un dispositivo de IA. Este no debe permanecer confundido con la naturalidad del pensamiento del juez, sino, en todo caso, bien diferenciado porque bien puede ser un apoyo, pero no un usurpador mimetizado en las palabras y pensamientos del juzgador.

Las neurotecnologías no portan nuevos derechos, solamente generan nuevas circunstancias de vida para la expansión de la interpretación y aplicación de los mismos derechos que, cuando son fundamentales, son siempre los ordenados en la línea de la libertad o de la dignidad y, cuando son fundamen- 
tales procesales, qué duda cabe, son los derechos de acción y contradicción los portadores de esa libertad y dignidad en el proceso.

El enfoque de los riesgos por la investigación y aplicación de las neurotecnologías que pueden volcarse al proceso no es en realidad un asunto de derechos fundamentales, sino de garantías fundamentales. Para aclarar esto, conviene anotar lo siguiente: las garantías fundamentales son diferentes de los derechos fundamentales, pero ambos configuran la composición estructural de los principios fundamentales.

Un principio fundamental está conformado estructuralmente por la unión de un derecho fundamental, que es de titularidad de la persona humana, con una o más garantías fundamentales, que pesan sobre el Estado. Una garantía fundamental comprende el nexo causal o expresión deóntica (prohibición u obligación) que se prescribe como obrar negativo (Estado liberal) u obrar positivo (Estado social) y los derechos fundamentales son la descripción de la persona humana en la lectura constitucional de libertad (correlativa al Estado liberal) y dignidad (correlativa al Estado social), lectura que no es sino la fundamentalidad misma de la Constitución.

La fundamentalidad constitucional es la lectura normativa de la persona humana como libertad y dignidad que es causa-fin de la sociedad y del Estado. Y esto se desprende del artículo 1 de la Constitución peruana vigente que menciona la defensa de la persona humana, como esencia de libertad condicionante del Estado liberal, y al respeto de la dignidad humana como el fin supremo de la sociedad y del Estado. De modo que, se diferencia en la Constitución su parte orgánica de la dogmática, primando esta sobre aquella.

Es en la Constitución dogmática en la que el problema ético de las investigaciones y aplicaciones de las neurotecnologías se soluciona. Lo que en el ámbito procesal se proyecta desde el principio fundamental de acción que comprende la unión del derecho fundamental de acción, que es de contenido mixto (tanto libertad como dignidad), con un elenco múltiple de garantías tanto del Estado liberal (garantías liberales procesales, encabezadas por la de proceso justo) como del Estado social (garantías liberales sociales, encabezadas por la de tutela jurisdiccional).

Las garantías del Estado social están encabezadas, en la materia procesal, por la jurisdicción-garantía que es propia de la Constitución dogmática o axiológica y va unida - estructuralmente- al contenido de dignidad del derecho de acción. Por tanto, se expresa en el obrar positivo que pesa en el Estado para prestar tutela jurisdiccional (con múltiples manifestación del obrar del juez, por ejemplo, debe impulsar el proceso, debe emitir sentencia, debe motivar 
la sentencia, etc.), lo que no puede no implicar que el Estado debe proveer un aparato de justicia suficiente en todos los planos (últimas tecnologías, número y capacitación de jueces, infraestructura, legislación eficiente, etc.), esto significa jueces con la suficiente inteligencia para cumplir su función de manera solvente nunca menos de lo normal, pero tampoco más porque sobredimensionar la necesidad de inteligencia en el juez puede conducir a aceptar una $\mathrm{BCl}$ con la que una IA se encubre en la mente del juez. No es forzada, entonces, la garantía de un juez normalmente inteligente como contenido de la exigencia de su independencia cerebral y mental que, en todo caso, no es sino su independencia interna.

\section{LISTA DE REFERENCIAS}

Amoedo-Souto, C-A. (2018). El Derecho administrativo español ante las neurociencias y el neuroderecho: desarrollos y perspectivas. Ius et scientia, 4(1), 84-106. https://revistascientificas.us.es/index.php/ies/article/view/13301 https://doi.org/10.12795/IETSCIENTIA.2018.101.06

Fraundorfer, M. (2018). The Rediscovery of Indigenous Thought in the Modern Legal System: The Case of the Great Apes. Global Policy. https://doi. org/10.1111/1758-5899.12517

Gava, G. M. (2010). Le neuroscienze e l'illusione della libertà. Cleup.

Harari, Y. N. (2016). Homo Deus. Breve historia del mañana. Debate Penguin Random House.

lenca, M. y Andorno, R. (2017). Towards new human rights in the age of neuroscience and neurotechnology. Life Sciences, Society and Policyk, 13(5). https:// doi.org/10.1186/s40504-017-0050-1

Kurzwell, R. (2012). La singularidad está cerca. Cuando los humanos transcendamos la biología. Lola Books.

Nieva, J. (2013). "Proceso judicial y neurociencia: una revisión conceptual del derecho procesal". En M. Taruffo y J. Nieva Fenoll (dirs.), Neurociencia y proceso judicial. Marcial Pons.

Picozza, E.; Capraro, L.; Cuzzocrea, V. y Terracina, D. (2014). Neurodiritto: Una introduzione, Giappichelli.

Solaiman, S. M. (2017). Legal personality of robots, corporations, idols, and chimpanzees: a quest for legitimacy. Artif Intell Law, 25, 155-179. https://doi. org/10.1007/s10506-016-9192-3

Waal, F. de. (2007). Primates y filósofos. La evolución de la moral del simio al hombre. Paidós. 
Widow, J. L. y Jensen, S. (2016). "Transhumanismo, mejoras y naturaleza humana". En M. Figueroa y J. L. Widow (eds.), Ética filosófica. Aproximaciones contemporáneas. RIL Editores.

Wolpaw Jr. et al. (2019). Brain-computer interfaces for communication and control. Clinical Neurophysiology, 113(6), 767-791. https://doi.org/10.1016/S13882457(02)00057-3

Yuste, R.; Goering, S. Agüera y Arcas, B.; Bi, G.; Carmena, J. M.; Carter, A.; Fins, J. J.; Friesen, P.; Gallant, J.; Huggins, J. E.; Illes, J.; Kellmeyer, P.; Klein, E.; Marblestone, A.; Mitchell, C.; Parens, E.; Pham, M.; Rubel, A.; Sadato, N.; Sullivan, L. S.; Teicher, M.; Wasserman, D.; Wexler, A.; Whittaker, M. y Wolpaw, J. (2017). Yuste, R. y Goering, S. (2017). Four ethical priorities for neurotechnologies and Al. Nature, 551, 159-163. https://doi.org/10.1038/551159a

Yuste, R., Genser, J. y Herrmann, S. (2021). It's Time for Neuro-Rights- New Human Rights for the Age of Neurotechnology. Horizons, 551, 154-164. https://doi. org/10.1038/551159a 